\title{
MANEJO AVERSIVO EM BOVINOS LEITEIROS E EFEITOS NO BEM-ESTAR, COMPORTAMENTO EASPECTOS PRODUTIVOS
}

\author{
AVERSIVE MANAGEMENT IN DAIRY CATTLE AND EFFECTS ON WELL-BEING, \\ BEHAVIOUR AND PRODUCTIVE ASPECTS
}

\author{
Peters, M.D.P. ${ }^{1 A \star}$, Barbosa Silveira, I.D. ${ }^{1 B}$, Pinheiro Machado Filho, L.C. ${ }^{2}$, Machado, A.A. ${ }^{3}$ \\ e Pereira, L.M.R. ${ }^{4}$
}

\begin{abstract}
${ }^{1}$ Faculdade de Agronomia Eliseu Maciel. Universidade Federal de Pelotas-FAEM-UFPel. Pelotas, RS. Brasil. A*monipaulapeters@yahoo.com.br, Bbardi@supersul.com.br

${ }^{2}$ Departamento de Zootecnia. Universidade Federal de Santa Catarina-UFSC. Florianópolis, SC. Brasil. ${ }^{3}$ Departamento de Matemática, Estatística e Informática. Instituto de Física e Matemática. Universidade Federal de Pelotas-IFM-UFPel. Pelotas, RS. Brasil.

${ }^{4}$ Conjunto Agrotécnico Visconde da Graça. Universidade Federal de Pelotas. CAVG-UFPel. Pelotas, RS. Brasil.
\end{abstract}

\section{PalaVRas ChaVE ADICIONAIS}

Etologia. Leite. Tratador. Vacas.

\section{RESUMO}

Este estudo avaliou os efeitos do manejo, aversivo e não aversivo, na condução de vacas da raça Holandês, através das seguintes variáveis: reatividade $(\mathrm{Re})$, defecação $(\mathrm{De})$, micção $(\mathrm{Mi})$, tempo de permanência na sala de ordenha (TPO), tempo de ordenha (TOR), produção de leite (PL), composição química do leite e contagem de células somáticas (CCS). Utilizou-se 32 vacas, com idade entre 60 e 96 meses, criadas em sistema semiintensivo, submetidas aos seguintes tratamentos, segundo um delineamento blocos casualizados: $\mathrm{T} 1=$ manejo aversivo e $\mathrm{T} 2=$ manejo não aversivo. Foram encontradas diferenças significativas para reatividade $(p<0,0001)$, defecação $(p=0,0208)$ e micção $(p=0,0007)$. Vacas manejadas aversivamente foram mais reativas e apresentaram maior ocorrência de defecação na sala de ordenha. No entanto, vacas submetidas ao manejo aversivo apresentaram menor ocorrência de miç̧ão. Houve interação significativa $(p<0,0001)$ entre os tipos de manejos e os dias com relação ao TPO e TOR. $\mathrm{Na}$ produção de leite a interação entre manejo e idade foi significativa ( $p=0,0062)$, de maneira que vacas com idade média de 60 meses submetidas ao manejo aversivo apresentaram menor produção de leite do que as submetidas ao não aversivo, com valores de 8,68 kg/leite/dia e 11,50 kg/leite/

Recibido: 18-4-08. Aceptado: 4-2-09.

\author{
AdDitional KEYWORDS \\ Ethology. Milk. Handler. Cows.
}

dia, respectivamente. Não foram encontradas diferenças significativas para os componentes do leite e contagem de células somáticas. O manejo aversivo altera o comportamento das vacas na sala de ordenha, prejudicando o bem-estar animal, com redução na produção de leite de vacas com idade média de 60 meses.

\section{SUMMARY}

This study evaluated the effects of aversive and non-aversive management on behaviour of Holstein cows for the following variables: reactivity $(\mathrm{Re})$, defecation (De), urination (Mi), time spent in the milking parlour (TPO), duration of milking (TOR), milk production $(\mathrm{PL})$, chemical composition of milk and somatic cells counting (CCS). Thirty two 6096 months old Holstein cows, raising under semiextensive system were used and submitted to the following treatments, in complete randomized blocks: $\mathrm{T} 1=$ aversive management and $\mathrm{T} 2=$ nonaversive management. Significant differences were found between managements for reactivity $(p<0.0001)$, defecation $(p=0.0208)$ and urination $(p=0.0007)$. Cows aversively managed were the most reactive and showed the highest occurrence of defecation in the milking parlour. However, 
cows submitted to aversive management showed the lowest occurrence of urination in the milking parlour. There was significant interaction $(p<0.0001)$ for management and days, regarding to TPO and TOR. For milk production there was significant interaction $(p=0.0062)$ between management and cow age. Cows averaging 60 months of age, submitted to aversive management produced less milk than cows non-aversively managed ( $8.68 \mathrm{~kg}$ milk/day and $11.50 \mathrm{~kg}$ milk/day), respectively. No significant differences were found for milk components and somatic cells. The aversive management alters the behaviour of dairy cows in the milking parlour, affecting the animal well-being and reducing milk production of cows with an average age of 60 months.

\section{INTRODUÇÃO}

Com o processo de domesticação dos animais de produção, intensificou-se a interação humano-animal. Havendo estudo que associou a interação com animais a uma melhor qualidade de vida para o homem (Blackshaw, 1996).

Na bovinocultura leiteira existe intensa interação entre humanos e animais, pois tratadores e vacas interagem diariamente durante o desenvolvimento de atividades de rotina, como ordenha, alimentação e cuidados sanitários (Hemsworth e Coleman, 1998). Alguns pesquisadores não reconhecem o relacionamento entre humanos e bovinos como valioso para ambas as partes, pois apontam os bovinos puramente como objetos de trabalho, que não se alteram com a qualidade da interação desenvolvida pelo homem. Apesar desta contradição, pesquisas têm sido desenvolvidas visando conhecer melhor as relações entre humanos e animais de produção (Rosa, 2002 e 2004; Hötzel et al., 2005). Breuer et al. (2000) encontraram que o tipo de interação no momento da ordenha pode causar mudanças comportamentais da vaca na ordenha. Interações negativas resultaram em maior reatividade, apesar da produção de leite não ter sido alterada. Entretanto, Hemsworth et al. (2000) não confirmam tal conclusão, uma vez que a interação negativa, durante a ordenha, foi negativamente correlacionada com a produção de leite e teores de proteína e gordura e positivamente correlacionada com a concentração de cortisol, o que indica a possibilidade de aumentar a produtividade através de interação positiva ordenhador e vaca leiteira.

Desta maneira, os reais efeitos da interação homem-animal nos sistemas de produção de leite ainda não estão bem explicados e entendidos. Além disso, a interação homem-animal na condução dos animais ainda não foi estudada, sendo a condução uma etapa importante do manejo, pois de acordo com a natureza da interação (positiva, neutra ou negativa/aversiva) pode-se encontrar diferentes respostas dos animais, com efeitos no bem-estar animal e, consequentemente, na produtividade, pois segundo Paranhos da Costa (2000), animais em situação de bem-estar são mais produtivos. Portanto, o objetivo deste trabalho foi avaliar o efeito do manejo, aversivo e não aversivo, na condução das vacas da sala de espera para a ordenha, sobre o bem-estar, comportamento e aspectos produtivos e qualitativos do leite de vacas da raça Holandês.

\section{MATERIAL EMÉTODOS}

O trabalho foi desenvolvido durante 24 dias no setor leiteiro do Conjunto Agrotécnico Visconde da Graça da Universidade Federal de Pelotas (Brasil), no período de maio a junho de 2007.

Foram utilizadas 32 vacas da raça Holandês, com idade entre 60 e 96 meses, estádios de lactação variando de 20 a 635 dias em lactação, produção de leite média de 9,8 $\pm 3,6$ litros/dia, submetidas aos tratamentos: manejo aversivo e manejo não aversivo, segundo um delineamento de blocos casualizados. A idade dos animais foi o fator de variação utilizado para o bloqueamento, resultando em dois blocos, um com idade média de 60 meses e outro com

Archivos de zootecnia vol. 59, núm. 227, p. 436. 


\section{EFEITO DO MANEJO AVERSIVO EM BOVINOS LEITEIROS}

idade média de 96 meses. Dentro dos blocos, separadamente, os tratamentos foram casualizados às unidades experimentais. A vaca foi considerada a unidade experimental, resultando em dezesseis repetições por tratamento.

O tratamento aversivo consistiu em bater com vara, conduzir com gritos, e não respeitar a velocidade de deslocamento dos animais para a sala de ordenha (Adaptado de Hötzel et al., 2005). As ações de manejo características do aversivo foram adaptadas com base no manejo rotineiro e efetivamente aplicado em boa parte das propriedades leiteiras da região Sul, justificando assim a escolha das ações de manejo citadas anteriormente. $\mathrm{O}$ tratamento não aversivo consistiu em não promover estimulação ativa às vacas, ou seja, não era empregada nenhuma ação positiva ou negativa na condução dos animais.

Para identificação dos animais utilizouse fitas de tecido amarradas ao pescoço, de cores diferentes de acordo com o tratamento, onde os animais submetidos ao manejo aversivo e ao não aversivo usavam fita de cor roxa e amarela, respectivamente. Do campo para a sala de espera os animais foram conduzidos por um funcionário, de forma tranqüila, sem gritos, respeitando a velocidade de deslocamento e na sala de espera separados, pelo mesmo funcionário do campo, em dois lotes, de acordo com os tratamentos, permanecendo em piquetes separados até a entrada na sala de ordenha. Os piquetes eram distantes, não possibilitando às vacas do manejo não aversivo enxergar as ações de manejo aplicadas as vacas do manejo aversivo. Os tratamentos foram aplicados na condução dos animais da sala de espera para a ordenha, sendo o manejo aversivo aplicado por uma pessoa que vestia uniforme azul e o manejo não aversivo executado por outra pessoa vestindo roupas de cor preta e rosa. Os tratadores que aplicaram o tratamento aversivo e o não aversivo eram desconhecidas dos animais, e utilizaram sempre as mesmas roupas. O tratador que aplicava o tratamento não entrava na sala de ordenha em nenhum momento, permanecendo na sala de espera apenas durante a condução dos animais alocados ao respectivo tratamento e após a execução do manejo este se ausentava do local de condução e de ordenha.

O manejo alimentar foi igual para todos os animais, consistindo de arraçoamento duas vezes ao dia, após as ordenhas com concentrado comercial para vacas em lactação e campo natural melhorado, com a presença predominantemente de gramaseda (Cynodon dactylon), capim anoni (Eragrostis plana), azévem anual (Lolium multiflorum) e trevo branco (Trifolium repens), caracterizando um sistema semiintensivo. As ordenhas foram realizadas duas vezes ao dia, manhã (6-8 h) e tarde (15$17 \mathrm{~h}$ ), em sala unilateral com quatro lugares, por dois funcionários que já trabalhavam a dez anos na propriedade. O manejo de ordenha executado caracterizava-se pela presença dos dois funcionários na sala de ordenha, cada um ordenhando duas vacas, igualdade na maneira de interagir com os animais e tranqüilidade na execução das atividades de rotina, sem utilização de gritos, tapas ou qualquer outro tipo de ação que influenciasse o comportamento do animal.

As avaliações foram sempre realizadas por um observador treinado utilizando amostragem scan (Roll et al., 2006). Foram registradas: reatividade $(\mathrm{Re})$, ocorrência de defecação (De), ocorrência de micção (Mi), tempo de permanência na sala de ordenha (TPO), tempo de ordenha (TOR), adaptado de Rosa (2002). Foram avaliadas as produções de leite, a composição química e a contagem de células somáticas do leite de cada animal.

A reatividade foi registrada durante a preparação do úbere, desde a pré-desinfecção das tetas, fixação e retirada das teteiras e desinfecção pós-ordenha, sendo considerada uma resposta comportamental que demonstra a condição de estresse que o animal está naquele momento. Realizado através da movimentação dos membros

Archivos de zootecnia vol. 59, núm. 227, p. 437. 
posteriores, com o seguinte escore: Reatividade $1=$ membros imóveis; Reatividade $2=$ membros posteriores em movimento, sem levantá-los acima de $15 \mathrm{~cm}$ do solo; Reatividade $3=$ membros posteriores em movimento, levantando-o em direção ao ordenhador. Os valores correspondem a uma escala nominal de 1 a 3 , onde animais com maiores valores de escore foram classificados como mais reativos.

A defecação e micção foram registradas durante o tempo de permanência na sala de ordenha, ou seja, a partir da entrada do animal na sala de ordenha até o momento da saída, através da ocorrência ou não (sim ou não), não sendo registrado o número de vezes que ocorreu o evento.

Os tempos de permanência na sala de ordenha (TPO) e tempo de ordenha (TOR) foram registrados individualmente. As medidas de TPO foram realizadas através do registro da hora de entrada da vaca na sala de ordenha e da hora de saída da sala, por diferença se obteve o tempo, em minutos, que a vaca permaneceu na sala de ordenha. Para as medidas de TOR registrou-se a hora da colocação das teteiras e a hora da retirada das mesmas, e por diferença se obteve o tempo de ordenha em minutos.

A produção de leite foi medida individualmente duas vezes por semana, na ordenha da manhã e tarde, através de medidor automático instalado em cada unidade de ordenha (kg de leite/vaca/ordenha). Semanalmente foram coletadas amostras individuais de leite, na ordenha da manhã, e posteriormente enviadas ao Laboratório de Qualidade do Leite da Embrapa Clima Temperado para determinação dos teores de proteína, gordura, sólidos totais e contagem de células somáticas.

Foi adotado o delineamento experimental blocos completos casualizados com medidas repetidas no tempo, sendo a idade dos animais utilizada para formação dos blocos e o estádio de lactação utilizado como co-variável na análise. As variáveis discretas, Re, De, Mi, foram submetidas à análise não paramétrica através do teste Cochran-Mantel-Haenzel para verificar a associação do manejo com estas respostas comportamentais. As variáveis TPO, TOR, produção de leite, teores de proteína, gordura, sólidos totais e contagem de células somáticas foram submetidos à análise da variância, através do procedimento GLM, SAS (1989). A variável produção de leite foi corrigida para 4\% de gordura (NRC, 2001) e os dados de contagem de células somáticas transformados pela aplicação de logaritmo natural. O nível mínimo de significância para rejeição da hipótese de nulidade foi de 0,05 .

Tabela I. Porcentagem de escores de reatividade, defecação e micção em vacas submetidas ao manejo aversivo e ao não aversivo. (Reactivity scores percentages, defecation and urination for cows submitted to aversive and non-aversive management).

\begin{tabular}{lccccccc}
\hline & \multicolumn{2}{c}{ Reatividade } & \multicolumn{2}{c}{ Defecação } & \multicolumn{2}{c}{ Micção } \\
Manejo & Re1 & Re2 & Re3 & Não & Sim & Não & Sim \\
\hline Aversivo* & $39,69(458)$ & $86,80(263)$ & $100(13)$ & $49,29(693)$ & $64,06(41)$ & $50,66(725)$ & $23,08(9)$ \\
Não aversivo* & $60,31(695)$ & $13,20(41)$ & $0(0)$ & $50,71(712)$ & $35,94(23)$ & $49,34(707)$ & $76,92(29)$ \\
p>CMH & & $<0,0001$ & & 0,0208 & 0,0007 \\
\hline
\end{tabular}

Valores de $\mathrm{p}<0,05$ diferem significativamente pelo teste de Cochran-Mantel-Haenzel.

Re1= membros imóveis; Re2= membros posteriores em movimento, sem levantá-los acima de $15 \mathrm{~cm}$ do solo; Re3= membros posteriores em movimento, levantando-o em direção ao ordenhador. *entre parênteses número de observações por categoria.

Archivos de zootecnia vol. 59, núm. 227, p. 438. 


\section{EFEITO DO MANEJO AVERSIVO EM BOVINOS LEITEIROS}

\section{RESULTADOSEDISCUSSÃO}

Foram encontradas (tabela I) diferenças significativas entre os manejos quanto às variáveis: reatividade $(\mathrm{p}<0,0001)$, defecação $(p=0,0208)$ e micção $(p=0,0007)$.

Os animais submetidos ao manejo aversivo apresentaram maior reatividade que os animais submetidos ao manejo não aversivo. Estes resultados corroboram os descritos por Rosa et al. (2004), que encontraram maior movimentação dos membros posteriores durante a ordenha quando foi utilizada a ação bater na condução das vacas da sala de espera para a ordenha, demonstrando certo nível de estresse. Segundo Breuer et al. (2000), a inquietação durante a ordenha pode ser conseqüência das ações negativas e velocidade do movimento dos tratadores ao conduzir o rebanho. A reatividade pode ser a expressão individual do animal a algum estímulo estressor (Rosa, 2002), sendo, neste caso, as ações de manejo aversivas executadas na condução da sala de espera para a ordenha o estímulo estressor, que repercutiu em efeitos no comportamento da vaca durante a ordenha.

As vacas submetidas ao manejo aversivo apresentaram maior ocorrência de defecação na sala de ordenha que às vacas submetidas ao manejo não aversivo. Devido a todos os animais permaneceram nas mesmas condições de alimentação, de manejo de campo e de ordenha a defecação registrada na sala foi considerada como resultante do estresse provocado pelo manejo aversivo na condução da sala de espera para a ordenha. A maior ocorrência de defecação por vacas manejadas aversivamente reflete um dos efeitos de situações de medo, pois segundo Argenzio (2006), animais com medo defecam freqüentemente, presumivelmente pela facilitação do reflexo por centros no cérebro. Os resultados corroboram os de Seabrook (1994), onde vacas sob tratamento aversivo na sala de ordenha defecaram seis vezes mais que vacas tratadas gentilmente.
A ocorrência de micção na sala de ordenha foi menor nas vacas submetidas ao manejo aversivo em relação às vacas do manejo não aversivo. Este resultado foi contrário a hipótese do trabalho de que vacas manejadas aversivamente teriam maior ocorrência de micção na sala de ordenha, mas cabe ressaltar que a micção é estimulada pelo deslocamento dos animais. Nas condições do experimento, os animais submetidos ao manejo não aversivo eram conduzidos do piquete de separação diretamente para a ordenha. Desta forma, este deslocamento pode ter estimulado a micção na sala, causando confundimento com a micção resultante da ação do tratador, que seria um indicador de estresse. Segundo Rosa (2004), vacas urinaram mais na sala de ordenha quando conduzidas do pasto diretamente para a sala, corroborando que a micção é estimulada pelo deslocamento.

Houve interação significativa com relação ao tempo de permanência na sala de ordenha (figura 1) e tempo de ordenha (figura 2) entre os manejos e os dias ( $p<0,0001)$, demonstrando variação do TPO e TOR de acordo com o dia. Observou-se, numericamente, maior TPO e maior TOR em vacas submetidas ao manejo não aversivo $(\mathrm{TPO}=9,6$ min e $\mathrm{TOR}=7,3$ min para o não aversivo e TPO=9,2 $\mathrm{min}$ e $\mathrm{TOR}=7,0 \mathrm{~min}$ para o aversivo). Este maior TPO em animais submetidos ao manejo não aversivo pode ser devido ao manejo tranqüilo e o respeito à velocidade de deslocamento dos animais, o que aumentou o tempo até os animais se acomodarem na sala. Com relação ao TOR, a menor quantidade de leite produzido pelos animais submetidos ao manejo aversivo, diminuiu os tempos de ordenha destes animais, pois vacas com menor produção são ordenhadas em menos tempo do que vacas de maior produção.

Analisando o TPO, verificou-se ausência de diferenças entre os manejos nos últimos quatro dias do experimento. Resultados semelhantes foram encontrados para TOR, onde a diferença deixou de existir nos últi- 


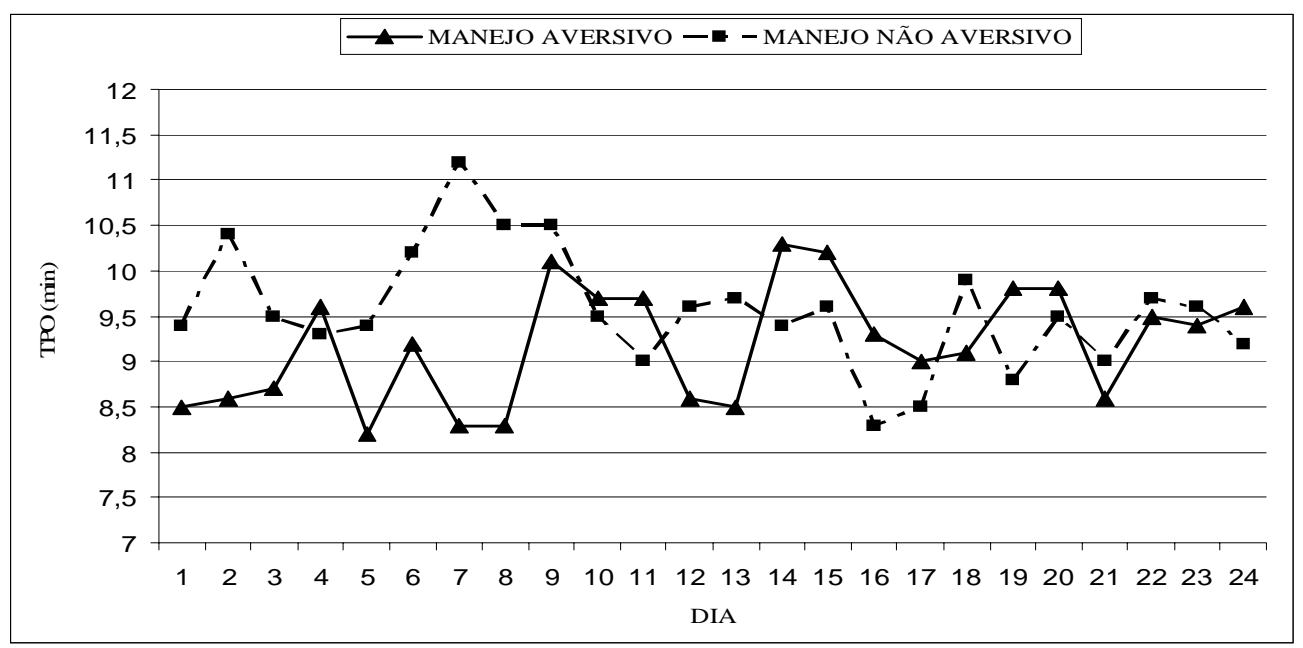

Figura 1. Médias da interação dia x tratamento, no tempo de permanência na sala de ordenha (TPO) dos animais submetidos ao manejo aversivo e ao não aversivo. (Day x treatment interaction average, for time spent in milking parlour (TPO) of animals submitted to aversive and non-aversive management).

mos sete dias. Ou seja, manejar os animais de forma aversiva ou não aversiva não causa efeitos nos TPO e TOR a partir de certo tempo de exposição ao estímulo estressor, caracterizando como acostumação, ou seja, o estímulo continua sendo aversivo, mas os animais deixam de responder a este.

Quanto à produção de leite, ocorreu interação significativa $(\mathrm{p}=0,0062)$ entre os manejos e as idades (tabela II). Os resulta-

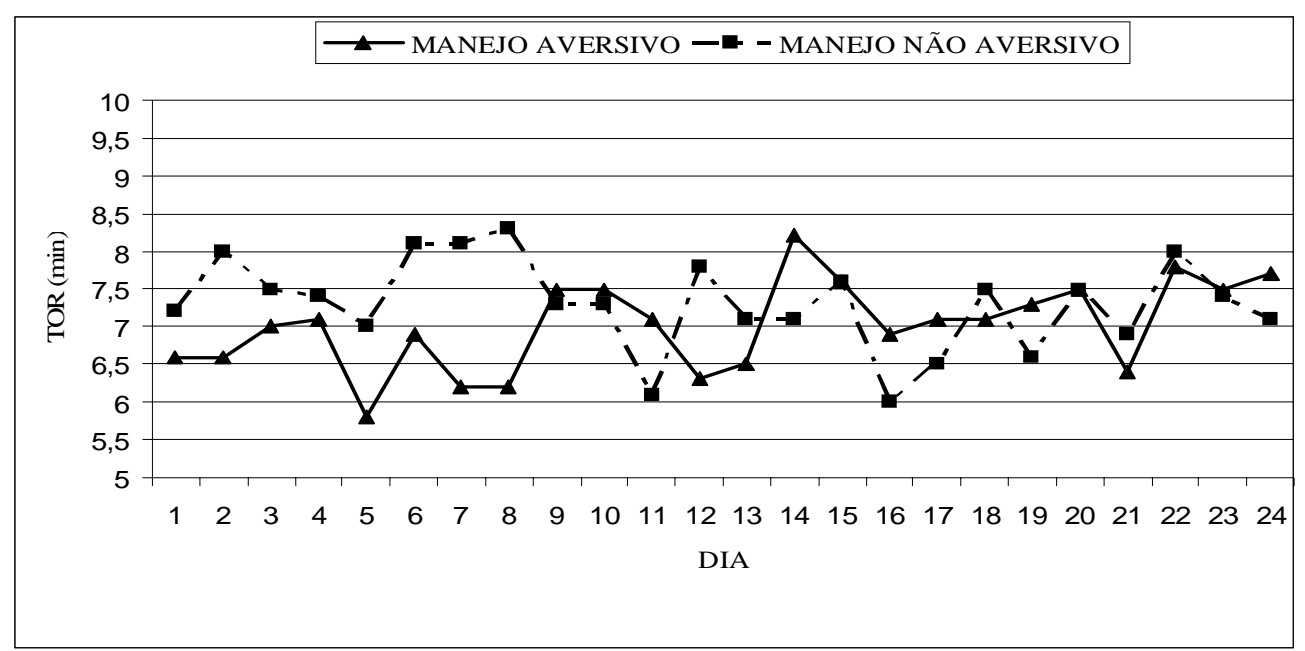

Figura 2. Médias da interação dia x tratamento, no tempo de ordenha (TOR) dos animais submetidos ao manejo aversivo e ao não aversivo. (Day x treatment interaction average, for milking time (TOR) of animals submitted to aversive and non-aversive management).

Archivos de zootecnia vol. 59, núm. 227, p. 440. 
Tabela II. Valores médios da interação idade $x$ tratamento e erros padrão (ep), na produção diária de leite dos animais submetidos ao manejo aversivo (A) e ao manejo não aversivo (NA). (Age $\mathrm{x}$ treatment interaction (with standard errors) average values, for daily milk production of animals submitted to aversive (A) and non-aversive (NA) management).

\begin{tabular}{lcccc}
\hline \multirow{2}{*}{ Variável } & \multicolumn{2}{c}{ Idade 1 } & \multicolumn{2}{c}{ Idade 2 } \\
& A & NA & A & NA \\
\hline PI diária kg & $8,68^{\mathrm{c}}$ & $11,50^{\mathrm{a}}$ & $9,47^{\mathrm{bc}}$ & $10,08^{\mathrm{b}}$ \\
ep & 0,40 & 0,40 & 0,40 & 0,40 \\
\hline
\end{tabular}

a,b,c médias seguidas de letras diferentes apresentam diferença significativa pelo teste $\mathrm{F}$ $(\alpha=0,05)$.

Idade média 1: 60 meses, 2: 96 meses.

dos demonstram que o manejo aversivo reduziu a produção de leite das vacas com idade média de 60 meses, quando comparado aos animais, de mesma idade, submetidos ao manejo não aversivo. Vacas com idade média de 96 meses não apresentaram diferenças significativas entre os manejos com relação à produção de leite.

Estes resultados podem estar relacionados à experiência prévia dos animais, pois vacas com idade média de 96 meses, provavelmente, já passaram por experiências negativas anteriores. Já as vacas com idade média de 60 meses, apresentam pouca ou nenhuma experiência de situação negativa ocorrida anteriormente em sua vida, sendo o estímulo estressor, neste caso o manejo aversivo, mais efetivo nestes animais. Estudos que evidenciam os efeitos da idade no desenvolvimento de respostas comportamentais e produtivas em vacas ainda são escassos, havendo apenas trabalhos (Lauber et al., 2006) que abordam os efeitos da idade em terneiros. Desta forma, são necessários maiores estudos que demonstrem os efeitos de manejo em vacas com diferentes idades.

A redução na produção de leite de vacas submetidas ao manejo aversivo, com idade média de 60 meses, pode ser explicada fisiologicamente, pois o reflexo de ejeção do leite é inibido por diversos estímulos causadores de estresse, como distúrbios emocionais, dor e medo. O estresse aumenta a liberação das catecolaminas (epinefrina e norepinefrina), as quais provocam a contração dos músculos lisos, resultando em oclusão parcial dos ductos mamários e dos vasos sanguíneos, impedindo assim que a ocitocina alcance as células mioepiteliais (Park e Lindberg, 2006). Portanto, o estresse provocado pelo manejo aversivo pode ter afetado o reflexo de ejeção do leite em vacas com idade média de 60 meses, inibindo a descida do leite e, consequentemente, aumentando o leite residual e diminuindo a quantidade de leite produzida por estes animais.

Não foram detectadas variações significativas nos teores de gordura, proteína, sólidos totais e contagem de células somáticas do leite entre os manejos (tabela III). Verificou-se que o estresse causado pelo manejo aversivo na condução das vacas da sala de espera para a ordenha não afetou os componentes do leite e contagem de células somáticas, provavelmente devido

Tabela III. Valores médios e coeficientes de variação da composição química do leite e contagem de células somáticas dos animais submetidos ao manejo aversivo e ao não aversivo. (Average values and coefficient of variation for milk chemical composition and somatic cells count of animals submitted to aversive and non-aversive management).

\begin{tabular}{lccc}
\hline Variáveis & A & NA & CV \\
\hline \% Gordura & $3,96^{\mathrm{a}}$ & $3,87^{\mathrm{a}}$ & 12,04 \\
\% Proteína bruta & $3,51^{\mathrm{a}}$ & $3,31^{\mathrm{a}}$ & 15,95 \\
\% Sólidos totais & $12,59^{\mathrm{a}}$ & $12,17^{\mathrm{a}}$ & 11,83 \\
CCS (cel/ml x 1000) & $392,24^{\mathrm{a}}$ & $329,96^{\mathrm{a}}$ & 22,07
\end{tabular}

amédias seguidas de letras iguais não apresentam diferença significativa pelo teste $F(\alpha=0,05)$. CV: Coeficiente de variação.

Archivos de zootecnia vol. 59, núm. 227, p. 441. 
a curta duração do tratamento, onde o estímulo estressor não foi suficiente para causar alterações.

\section{CONCLUSÕES}

O manejo aversivo na condução das vacas da sala de espera para a ordenha resulta em animais mais reativos e com maior ocorrência de defecação na sala, alterando o comportamento, prejudicando o bem-es-

\section{BIBLIOGRAFIA}

Argenzio, R.A. 2006. Motilidade gastrintestinal. Em: Dukes: Fisiologia dos animais domésticos. Ed. Guanabara Koogan S.A., $12^{a}$ edição. Rio de Janeiro. pp. 362-373.

Blackshaw, J. 1996. Developments in the study of human-animal relationships. Appl. Anim. Behav. Sci., 47: 1-6.

Breuer, K., Hemsworth, P.H., Barnett, J.L., Matthews, L.R. and Coleman, G.J. 2000. Behavioural response to humans and the productivity of commercial dairy cows. Appl. Anim. Behav. Sci., 66: 273-288.

Hemsworth, P.H. and Coleman, G.J. 1998. Humanlivestock interactions: the stockperson and the productivity and welfare of intensively farmed animals. CAB International. London. 140 pp.

Hemsworth, P.H., Coleman, G.J., Barnett, J.L. and Borg, S. 2000. Relationships between humananimal interactions and productivity of commercial dairy cows. J. Anim. Sci., 78: 2821-2831.

Hötzel, M.J., Pinheiro Machado Filho, L.C., Yunes, M.C. e Silveira, M.C.A.C. 2005.Influência de um ordenhador aversivo sobre a produção leiteira de vacas da raça holandesa. Rev. Bras. Zootecn., 34: 1278-1284.

Lauber, M.C.Y., Hemsworth, P.H. and Barnett, J.L. 2006. The effects of age and experience on behavioural development in dairy calves. Appl. Anim. Behav. Sci., 99: 41-52.

NCR. 2001. National Reseach Council. Nutrient requirements of dairy cattle. National Academy Press. Ed. Washington, D.C. 381 pp.

Paranhos da Costa, M.J.R. 2000. Ambiência na produção de bovinos de corte. An. Etologia, tar animal, com diminuição da produção de leite em vacas com idade média de 60 meses, sem alterar as características químicas do leite e a contagem de células somáticas.

Para que a fazenda leiteira atenda as necessidades de bem-estar dos animais, facilite o manejo diário com as vacas e aumente os índices produtivos é necessário que as ações dos tratadores na condução dos animais da sala de espera para a ordenha sejam de ótima qualidade.

18: $1-15$.

Park, C.S. e Lindberg, G.L. 2006. Glândula mamária e lactação. Em: Dukes: Fisiologia dos Animais domésticos. Ed. Guanabara Koogan S.A., $12^{\mathrm{a}}$ edição. Rio de Janeiro. pp. 670-690.

Rosa, M.S. 2002. Interação entre retireiros e vacas leiteiras na ordenha. Dissertação (Mestrado em Zootecnia). Faculdade de Ciências Agrárias e Veterinárias. Universidade Estadual Paulista. Jaboticabal. 52 pp.

Rosa, M.S. 2004. Ordenha sustentável: a interação retireiro-vaca. Tese (Doutorado em Zootecnia). Faculdade de Ciências Agrárias e Veterinárias. Universidade Estadual Paulista. Jaboticabal. 83 pp.

Roll, V.F.B., Rech, C.L. de S., Xavier, E.G., Rech, J.L., Rutz, F. e Del Pino, F.A.B. 2006. Comportamento animal: conceitos e técnicas de estudo. Editora e Gráfica Universitária, UFPEL. Pelotas. 110 pp.

Rosa, M.S., Paranhos da Costa, M.J.R., Gonçalves, R.C., Madureira, A.P., Pereira, A.C.F. e Silva, L.C.M. 2004. A importância das ações dos retireiros na condução de vacas da sala de espera para a de ordenha. Em: XXII Encontro Anual de Etologia. Campo Grande. Anais... SBEt. Campo Grande.

SAS. 1989. SAS/STAT® User's Guide, Version 6, 4. v.2. Ed. SAS Institute Inc. Cary, NC. 846 pp. Seabrook, M.F. 1994. Psychological interaction between the milker and the dairy cow. In: International Dairy Housing Conference on Dairy Systems for the $21^{\text {st }}$ Century, 3. ASAE. Proceedings... Orlando. Orlando. pp. 49-58.

Archivos de zootecnia vol. 59, núm. 227, p. 442. 